\title{
Acute kidney injury after ingestion of rhubarb: secondary oxalate nephropathy in a patient with type 1 diabetes
}

Marc Albersmeyer ${ }^{1 *}$, Robert Hilge ${ }^{1}$, Angelika Schröttle ${ }^{1}$, Max Weiss ${ }^{2}$, Thomas Sitter ${ }^{1}$ and Volker Vielhauer ${ }^{1}$

\begin{abstract}
Background: Oxalosis is a metabolic disorder characterized by deposition of oxalate crystals in various organs including the kidney. Whereas primary forms result from genetic defects in oxalate metabolism, secondary forms of oxalosis can result from excessive intestinal oxalate absorption or increased endogenous production, e.g. after intoxication with ethylene glycol.

Case presentation: Here, we describe a case of acute crystal-induced renal failure associated with excessive ingestion of rhubarb in a type 1 diabetic with previously normal excretory renal function. Renal biopsy revealed mild mesangial sclerosis, but prominent tubular deposition of oxalate crystals in the kidney. Oxalate serum levels were increased.

Conclusion: Acute secondary oxalate nephropathy due to excessive dietary intake of oxalate may lead to acute renal failure in patients with preexisting renal disease like mild diabetic nephropathy. Attention should be payed to special food behaviors when reasons for acute renal failure are explored.
\end{abstract}

Keywords: Renal failure, Oxalate, Hyperoxaluria, Rhubarb, Malabsorption, Diabetes

\section{Background}

Oxalosis is a metabolic disorder characterized by deposition of oxalate crystals in various organs including the kidney. Primary and secondary forms of oxalosis can be distinguished. Primary oxalosis or hyperoxaluria $(\mathrm{PH})$ is caused by genetic disorders. The most common genetic defects comprise mutations in the genes encoding for alanin-glyoxylate-aminotransferase $(A G X T)$ resulting in $\mathrm{PH}$ type 1 , and glyoxylate-reductase/hydroxypyruvatreductase (GRHPR) causing PH type 2. Recently, a third gene defect leading to a deficiency of 4-hydroxy-2oxoglutarate aldolase (HOGA1) has been identified as the cause of PH type 3 [1]. Typically, disease manifestations occur in childhood or adolescence. Prognosis is poor, since approximately $50 \%$ of diagnosed patients progress to end-stage renal disease (ESRD). Treatment of primary forms comprises hemodialysis or peritoneal dialysis for

\footnotetext{
* Correspondence: Marc.Albersmeyer@med.uni-muenchen.de

'Nephrologisches Zentrum, Medizinische Klinik und Poliklinik IV, Campus Innenstadt, Klinikum der Ludwig-Maximilians-Universität München, Ziemssenstr. 1, 80336 Munich, Germany

Full list of author information is available at the end of the article
}

renal failure, yet cannot prevent progression of disease as elimination of oxalate by dialysis is insufficient. Therefore, combined kidney/liver transplantation is the treatment of choice [2].

Secondary forms of hyperoxaluria may result from increased intestinal oxalate absorption (termed enteric hyperoxaluria), endogenous production, or increased dietary intake. Enteric hyperoxaluria accounts for approximately $5 \%$ of all cases of hyperoxaluria and is associated with fat malabsorption due to small bowel disease or cystic fibrosis. The suggested mechanism leading to hyperoxaluria in these cases is a net loss of calcium via unresorbed bile acids, which in turn is not available to bind oxalate in the intestinal lumen. Calcium-bound oxalate is normally excreted via the feces, whereas unbound oxalate can be absorbed via the colonic mucosa [3]. Interestingly, bariatric surgery can increase oxalate absorption in the colon and thus may be an iatrogenic cause of hyperoxaluria [4]. Hyperoxaluria can also result from ingestion of ethylene glycol, high doses of vitamin $\mathrm{C}$ [5], or vitamin B6 deficiency [4] that result in increased 
endogenous production of oxalate. Other described causes include hyperparythyreoidism and sarcoidosis [6].

Here, we describe a case of acute renal failure after excessive ingestion of rhubarb in a type 1 diabetic with previously normal excretory renal function, with tubular deposition of oxalate crystals evident on renal biopsy.

\section{Case presentation}

The 52 year-old caucasian female patient suffered from reoccurring episodes of nausea and vomiting in the preceding days. With a known history of type 1 diabetes, the patient was admitted to clinic in a state of severe hypoglycemia. On admission an elevated serum creatinine was noted, with creatinine levels initially being $3.6 \mathrm{mg} / \mathrm{dl}$ and an estimated glomerular filtration rate (eGFR, according to the modified of diet in renal disease (MDRD) equation) of $13.3 \mathrm{ml} / \mathrm{min} / 1.73 \mathrm{~m}^{2}$. Postrenal causes were excluded by renal ultrasound which did not show any signs of obstructive nephropathy or intrarenal and ureteral concrements. Since the calculated fractional excretion of urea was $40.8 \%$ and renal function did not show improvement upon intravenous volume challenge, prerenal causes appeared unlikely and the patient was transferred to the nephrology department for further evaluation. The patient denied any use of nonsteroidal antirheumatic drugs (NSAR) such as diclofenac or ibuprofen, and she had not been exposed to contrast media recently.

The patient was diagnosed with diabetes type 1 several years ago and has been treated with insulin on an intensified conventional therapy (ICT) regimen. Previously, renal function was normal, with creatinine values remaining below $1.0 \mathrm{mg} / \mathrm{dl}$, corresponding to a eGFR > $60 \mathrm{ml} / \mathrm{min} / 1.73 \mathrm{~m}^{2}$ at routine consultations with her diabetologist. However, urinalysis several years ago showed a significant microalbuminuria of $100 \mathrm{mg} / \mathrm{dl}$ as tested by screeining dipstick analysis. Thus, chronic kidney disease (CKD) stage one according to "Kidney disease: Improving global outcomes" (KDIGO) had been diagnosed. The patient's medical history comprised a severe depression. Currently, she described a stable psychiatric situation, and had discontinued the pharmacological treatment with venlafaxin several months ago. There was no history of kidney stones both in the patient or her family. In addition, there was no history of small bowel disorders. Current medication of the patient included insulin and insulin glargin, as well as ramipril, metoprolol and lowdose aspirin. This medication has been taken for several years.

Physical examination revealed a 52-year-old patient in good physical condition. Blood pressure was slightly elevated $(145 / 76 \mathrm{mmHg})$, heart beat at regular rate and rhythm. She was breathing normally and was afebrile. There was no lymphadenopathy in the cervical, nuchal, supra- or infraclavicular regions. Skin examination was unremarkable. Mucous membranes were moist without signs of candidosis. Lung and heart auscultation were unremarkable. Jugular veins were slightly distended at $2 \mathrm{~cm}$ on both sides; however, no significant peripheral edema was present. Abdominal examination was unremarkable. The patient showed signs of lower leg varicosis bilaterally. Vascular status showed a lack of palpable pulses downstream of the popliteal artery on the left side, no foot ulcerations were noted. Neurological examination was unremarkable.

Laboratory testing showed a mild hyperchromic anemia (Hb $10.5 \mathrm{~g} / \mathrm{dl}$ ). Serum creatinine was $3.6 \mathrm{mg} / \mathrm{dl}$, corresponding to an eGFR of $13.3 \mathrm{ml} / \mathrm{min} / 1.73 \mathrm{~m}^{2}$ using the MDRD-equation (Table 1). The patient presented with hyperkalemia $(5.9 \mathrm{mmol} / \mathrm{l})$, hyperphosphatemia of $5.1 \mathrm{mg} / \mathrm{dl}$ (reference range $2.5-4.8 \mathrm{mg} / \mathrm{dl}$ ) and a mild hypercalcemia as revealed by a protein-corrected calcium value of $2.55 \mathrm{mmol} / \mathrm{l}$ (reference range $2.15-2.50 \mathrm{mmol} / \mathrm{l}$ ). Thyroid and liver function tests were unremarkable. Urine examination revealed a proteinuria of $3.7 \mathrm{~g}$ protein per g creatinine, being mostly albumin ( $2.6 \mathrm{~g} / \mathrm{g}$ creatinine). Intact parathyroid hormone was increased to $103 \mathrm{pg} / \mathrm{ml}$ (reference range 15-65 pg/ml). Urine microscopy showed no evidence for acanthocytes, erythrocyte casts, tubular casts or crystals. Autoantibody testing revealed a slightly elevated ANA-titer of 1:120, with normal values for complement. ANCA-antibodies and anti-GBM-antibodies were not detected.

A kidney biopsy was performed and showed mild diabetic mesangial sclerosis. Moreover, multiple birefringent crystallinous casts were found within the tubular lumen (Figure 1). No changes typical for ischemic renal failure were noted. Upon further questioning, the patient reported an increased ingestion of approximately $500 \mathrm{mg}$ of rhubarb (fresh weight) per day in the last 4 weeks. Consumption of vitamin $\mathrm{C}$ or ethylene glycol was denied. Additional laboratory tests revealed elevated serum oxalate levels $(13.75 \mu \mathrm{mol} / \mathrm{l}$, reference range $<6.5 \mu \mathrm{mol} / \mathrm{l})$, whereas urinary excretion of oxalate, glycolate, citrate and calcium were normal (Table 2). Serum levels of folic acid, as well as vitamin B12 were within the normal range. The patient underwent an ophthalmological examination which showed no evidence for corneal of retinal oxalate deposition.

The history of high oxalate intake, the elevated serum oxalate levels, and the histological detection of intratubular birefringent crystals lead to the diagnosis of secondary oxalosis, being the most likely cause for the acute decline in the patient's renal function. Since no established causative therapy for secondary oxalosis is available, intravenous fluid replacement was started, leading to an initial stabilization of renal function with an eGFR at $15 \mathrm{ml} / \mathrm{min} / 1.73 \mathrm{~m}^{2}$. However, upon 
Table 1 Laboratory data at presentation

\begin{tabular}{l} 
Variable \\
\hline Blood Count \\
Leukocytes (G/l) \\
Erythrocytes (T/) \\
Hemoglobin ( $/ \mathrm{dl})$ \\
Hematocrit (\%) \\
Mean corpuscular volume (fl) \\
Mean corpuscular hemoglobin (pg) \\
Mean corpuscular hemoglobin \\
concentration ( $/ \mathrm{dl})$ \\
Platelet count (G/l) \\
Serumchemistry \\
Sodium (mmol/l) \\
Potassium (mmol/l) \\
Glucose (mg/dl) \\
Urea nitrogen (mg/dl) \\
Creatinine (mg/dl) \\
Estimated glomerular filtration rate \\
(MDRD) (ml/min/1.73 m²) \\
Calcium (mg/dl) \\
Calcium (protein-corrected) (mmol/l) \\
Phosphorus (mg/dl) \\
C-reactive protein (mg/dl) \\
Total protein (g/dl) \\
Carbone dioxide (mmol/l) \\
(mtact paratyrold
\end{tabular}

Intact parathyroid hormone (pg/ml)

Urinalysis

\section{Screening dipstick test}

White cells (per $\mu$ l)

Nitrites

$\mathrm{pH}$

Protein $(\mathrm{mg} / \mathrm{dl})$

Glucose (mg/dl)

Ketones $(\mathrm{mg} / \mathrm{dl})$

Urobilinogen (mg/dl)

Bilirubin

Blood (per $\mu$ l)

Specific weight $(\mathrm{g} / \mathrm{l})$

\section{Sediment}

White cells (per high-power field)

Red cells (per high-power field)

Epithelial cells (per high-power field)

Hyaline casts (per low-power field)

Granulated casts (per low-power field)

Cellular casts (per low-power field)
Table 1 Laboratory data at presentation (Continued)

\begin{tabular}{lcc}
\hline Urinary chemistry & & \\
BUN (urine) (mg/dl) & $700.0-1213.0$ & 492 \\
Creatinine (urine) (mg/dl) & $30.0-220.0$ & 79.2 \\
Protein (urine) (mg/dl) & $<15.0$ & $\mathbf{2 9 6}$ \\
Protein/creatinine ratio (mg/g) & $<100.0$ & $\mathbf{3 , 7 4 0}$ \\
Albumin (urine) (mg/dl) & $<2.0$ & $\mathbf{2 1 0}$ \\
Albumin/creatinine ratio (mg/g)) & $<20.0$ & $\mathbf{2 , 6 4 5}$ \\
a1-Microglobulin (urine) (mg/l) & $<12.0$ & $\mathbf{1 0 6}$ \\
a1-Microglobulin/creatinine (mg/g) & $<14.0$ & $\mathbf{1 3 3}$ \\
Immunology & & \\
Monoclonal immunoglobulins & & negative \\
Complement C3 (mg/dl) & $90.0-180.0$ & 115 \\
Complement C4 (mg/dl) & $10.0-40.0$ & 31.7 \\
Antinuclear antibodies (ANA) & & $\mathbf{1 : 1 2 0}$ \\
Antineutrophil cytoplasmic antibodies (ANCA) & & negative \\
$\begin{array}{l}\text { Anti basal membrane antibodies (ELISA) } \\
\text { (IU/ml) }\end{array}$ & $<20.000$ & $<20.0$ \\
\hline Values outside the reference range are shown in bold print. & \\
\hline
\end{tabular}

2.15-2.50 2.53 discontinuation of the intravenous fluid regimen, cre$2.15-2.50 \quad 2.55$ atinine levels slowly rose to a maximum of $4.3 \mathrm{mg} / \mathrm{dl}$ 2.5-4.8 $\quad 5.1 \quad$ (eGFR $10.3 \mathrm{ml} / \mathrm{min} / 1.73 \mathrm{~m}^{2}$ ) within 2 months. Currently, $<0.50 \quad 0.18$ the patient is treated in our outpatient clinic for end 60-85 stage renal disease (ESRD), and options for fistulas are 6.0-8.5 7.6 being evaluated in preparation for hemodialysis.

$23.0-29.0 \quad 22.2$

$15-65 \quad 103$

\section{Discussion}

Apart from genetic forms of hyperoxaluria (PH1 to 3), hyperoxaluria and hyperoxalemia can occur upon increased dietary intake of foods that have a high oxalate content such as cocoa (mean oxalate content $700 \mathrm{mg} /$ $100 \mathrm{~g}$ fresh weight (FW) [7]), rhubarb (raw $805 \mathrm{mg} /$ $100 \mathrm{~g} \mathrm{FW}$, stewed $460 \mathrm{mg} / 100 \mathrm{~g}$ FW [7]), spinach (970 mg/100 g FW [7]), black teas (1150 mg/100 g FW [7]), beet leaves (610 mg/100 g FW [7]), and star fruit $(263 \mathrm{mg} / 100 \mathrm{~g} \mathrm{FW}$ [8]). Interestingly, there is some data that herbal medicines containing rhubarb might actually improve renal function, including the reduction of proteiuria, slowing progression of chronic kidney disease or ameliorating dyslipidemia [9]. Antiinflammatory and anti-fibrotic effects are discussed. It has not been reported that regular consumption of these preparations caused secondary hyperoxaluria and renal failure. Since ascorbic acid can be metabolized to oxalate, high intake of vitamin $\mathrm{C}$ may also cause hyperoxaluria [5].

Several cases of acute deterioration of renal function secondary to oxalate crystal deposition have been described with a majority comprising malabsorption syndromes such as pancreatitis or gastric by-pass as well as 

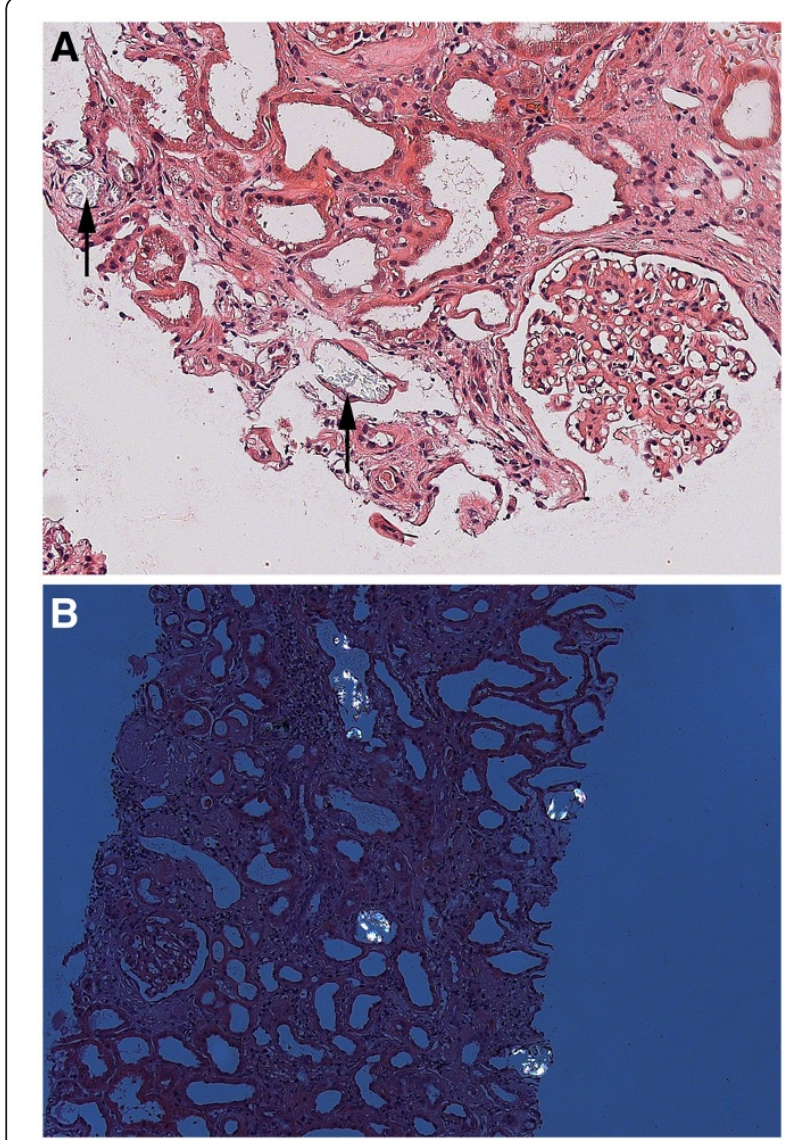

Figure 1 (A) Oxalate crystals (arrows) within the renal tubular lumen in a hematoxylin eosin-stained section (original magnification $\times 200$ ) and (B) under polarisation light microscopy (original magnification $\times 100$ ). Adjacent glomeruli show mild diabetic mesangial sclerosis.

non-renal organ transplant recipients [10-12]. Recent reports illustrated a deteriorated renal function after consumption of star fruit [13] or peanuts [14], both of which containing high amounts of oxalate. There are only few reports that described oral rhubarb ingestion as a cause of oxalate-induced kidney injury, most of which occurred in children [15].

Here, we report an adult patient with initially unexplained acute renal failure. Surprisingly, her kidney biopsy revealed deposition of disseminated crystals within the tubular lumen suggestive for calcium oxalate deposition.

Table 224 hour urine analysis

\begin{tabular}{lcc}
\hline Variable & Referance range & Result \\
\hline Oxalate $\left(\mathrm{mmol} / 1,73 \mathrm{~m}^{2} / \mathrm{d}\right)$ & $<0.5$ & 0.39 \\
Glycolate $\left(\mathrm{mmol} / 1,73 \mathrm{~m}^{2} / \mathrm{d}\right)$ & $<0.5$ & 0.34 \\
Citrate $(\mathrm{mmol} / \mathrm{d})$ & $0.3-7.4$ & 2.25 \\
Calcium $(\mathrm{mg} / \mathrm{d})$ & $<250$ & 176 \\
\hline
\end{tabular}

As no other causes of the patient's acute renal failure could be elucidated, she was carefully questioned regarding oxalate intake. She reported an extensive consumption of rhubarb, i.e. $500 \mathrm{mg}$ fresh weight of plant per day for the least 4 weeks. This resulted in an uptake of approximately 2.3 g oxalate per day [7]. In a study by Holmes et al. a dose of approximately $1 \mathrm{~g}$ oxalate was given to healthy subjects without evidence of acute renal injury or oxidative stress [16]. However, the minimal dose of oxalate causing death in adults is $4-5 \mathrm{~g}$ [15]. These cases often show typical birefringent oxalate deposition in the tubular lumen and in tubular epithelial cells [15]. To our knowledge, there is no data defining a threshold for oxalate intake that would result in nephropathy. Our patient had a known history of diabetes mellitus type 1 and chronic kidney disease stage I with microalbuminuria, but without a previous impairment of excretory renal function. We assume that in this patient a mildly injured diabetic kidney suffered a"second hit"by oxalate crystal deposition within tubuli leading to acute renal failure.

In addition, a prerenal component may have contributed to the acute kidney failure due to the initial episode of nausea and vomiting with a prolonged state of hypoglycemia. Importantly, there is evidence that reductions of GFR facilitate precipitation of calcium-oxalate crystals [17]. However, renal biopsy revealed no changes suggestive for prerenal or ischemic renal failure, but showed prominent oxalate crystal deposition. Thus, it is unlikely that dehydration was the primary cause that lead to a prerenal form of renal failure in this patient. Instead, the patient's initial episodes of nausea and vomiting could have been symptoms of her acute renal failure.

There are few data on long term-outcomes of patients with secondary oxalate nephropathy. A retrospective analysis of twelve French patients with acute oxalate nephropathy reported ESRD in three of 12 patients after a median follow-up of 7 months [10]. Therapeutic approaches are limited and comprise increased fluid intake, probiotics [18], low-oxalate diet [19] and hemodialysis or peritoneal dialysis for ESRD [20]. There is inconclusive data considering probiotic therapy. Of note, Oxalobacter formigenes colonizes the human intestine and relies on the metabolism of oxalate [3]. Several reports and small studies describe a potential benefit of Oxalobacter treatment on lowering both plasma and urinary oxalate levels [18,21]. Even though these data appear promising, there is still uncertainty about its efficacy and correct dosing, and larger studies are needed [22].

\section{Conclusion}

We report a rare case of acute secondary oxalate nephropathy, likely due to excessive ingestion of rhubarb in an 
adult with preexisting mild diabetic nephropathy, leading to crystal-induced acute renal failure. Thus, we recommend careful questioning of dietary habits or intoxications when reasons for acute renal failure are investigated. Moreover, patients with chronic renal functional impairment may be advised to avoid oral intake of excessive amounts of oxalate-containing foods such as rhubarb or spinach.

\section{Consent}

Written informed consent was obtained from the patient for publication of this case report and any accompanying images. A copy of the written consent is available for review by the Editor-in-Chief of this journal.

\section{Competing interests}

The authors declare that they have no competing interests.

\section{Authors' contributions}

$\mathrm{MA}, \mathrm{RH}, \mathrm{AS}, \mathrm{TS}$ and $\mathrm{W}$ treated the patient and provided data about the history and laboratory results. MW interpreted the kidney biopsy. MA and W drafted the manuscript. All authors read and approved the final manuscript.

\section{Acknowledgements}

We thank Dr. Lutz Weber, Department for Pediatric Nephrology for helpful discussions.

\section{Author details}

${ }^{1}$ Nephrologisches Zentrum, Medizinische Klinik und Poliklinik IV, Campus Innenstadt, Klinikum der Ludwig-Maximilians-Universität München, Ziemssenstr. 1, 80336 Munich, Germany. ${ }^{2}$ Pathologisches Institut, Ludwig-Maximilians-Universität München, Thalkirchner Str. 36, 80337 Munich, Germany.

Received: 10 April 2012 Accepted: 18 October 2012

Published: 30 October 2012

\section{References}

1. Hoppe B: The enzyme 4-hydroxy-2-oxoglutarate aldolase is deficient in primary hyperoxaluria type III. Nephrol Dial Transplant 2012, 27:3024-3026.

2. Hoppe B: An update on primary hyperoxaluria. Nat Rev Nephrol 2012, 8:467-475.

3. Siva S, Barrack ER, Reddy GPV, Thamilselvan V, Thamilselvan S, Menon M, Bhandari M: A critical analysis of the role of gut Oxalobacter formigenes in oxalate stone disease. BJU Int 2009, 103:18-21.

4. Bobrowski AE, Langman CB: Hyperoxaluria and systemic oxalosis: current therapy and future directions. Expert Opin Pharmacother 2006 7:1887-1896.

5. Lamarche J, Nair R, Peguero A, Courville C: Vitamin C-induced oxalate nephropathy. Int J Nephrol 2011, 2011:146927.

6. Rodman JS, Mahler RJ: Kidney stones as a manifestation of hypercalcemic disorders. Hyperparathyroidism and sarcoidosis. Urol Clin North Am 2000, 27:275-285. viii.

7. Noonan S: Oxalate content of foods and its effect on humans. Asia Pacific J Clin Nutr 1999, 8:64-74.

8. Tsai J-J, Huang CW, Wu J-K, Tony T, Lee Y: Comparison of oxalate content in foods and beverages in Taiwan. J Taiwan Urol Assoc 2005, 16:93-99.

9. Peng A, Gu Y, Lin SY: Herbal treatment for renal diseases. Ann Acad Med Singap 2005, 34:44-51.

10. Cartery C, Faguer S, Karras A, Cointault O, Buscail L, Modesto A, Ribes D, Rostaing L, Chauveau D, Giraud P: Oxalate nephropathy associated with chronic pancreatitis. Clin J Am Soc Nephrol 2011, 6:1895-1902.

11. Moutzouris D-A, Skaneli G, Margellos V, Apostolou T, Petraki C, Nikolopoulou $\mathrm{N}$ : Oxalate nephropathy in a diabetic patient after gastric by-pass. Clin Nephrol 2011, 75(Suppl 1):16-19.

12. Lefaucheur C, Hill GS, Amrein C, Haymann JP, Jacquot C, Glotz D, Nochy D: Acute oxalate nephropathy: a new etiology for acute renal failure following nonrenal solid organ transplantation. Am J Transplant 2006, 6:2516-2521.

13. Chen $\mathrm{CL}$, Fang HC, Chou KJ, Wang JS, Chung HM: Acute oxalate nephropathy after ingestion of star fruit. Am J Kidney Dis 2001, 37:418-422.

14. Sasaki M, Murakami M, Matsuo K, Matsuo Y, Tanaka S, Ono T, Mori N: Oxalate nephropathy with a granulomatous lesion due to excessive intake of peanuts. Clin Exp Nephrol 2008, 12:305-308.

15. Sanz $P$, Reig R: Clinical and pathological findings in fatal plant oxalosis. A review. Am J Forensic Med Pathol 1992, 13:342-345.

16. Holmes RP, Ambrosius WT, Assimos DG: Dietary oxalate loads and renal oxalate handling. J Urol 2005, 174:943-947.

17. Marangella M, Cosseddu D, Petrarulo M, Vitale C, Linari F: Thresholds of serum calcium oxalate supersaturation in relation to renal function in patients with or without primary hyperoxaluria. Nephrol Dial Transplant 1993, 8:1333-1337.

18. Hoppe B, Beck B, Gatter N, von Unruh G, Tischer A, Hesse A, Laube N, Kaul $P$, Sidhu $\mathrm{H}$ : Oxalobacter formigenes: a potential tool for the treatment of primary hyperoxaluria type 1. Kidney Int 2006, 70:1305-1311.

19. Lieske JC, Tremaine WJ, De Simone C, O'Connor HM, Li X, Bergstralh EJ, Goldfarb DS: Diet, but not oral probiotics, effectively reduces urinary oxalate excretion and calcium oxalate supersaturation. Kidney Int 2010 78:1178-1185

20. Illies F, Bonzel K-E, Wingen A-M, Latta K, Hoyer PF: Clearance and removal of oxalate in children on intensified dialysis for primary hyperoxaluria type 1. Kidney Int 2006, 70:1642-1648.

21. Hoppe B, Dittlich K, Fehrenbach H, Plum G, Beck BB: Reduction of plasma oxalate levels by oral application of Oxalobacter formigenes in 2 patients with infantile oxalosis. Am J Kidney Dis 2011, 58:453-455.

22. Borghi L, Nouvenne A, Meschi T: Probiotics and dietary manipulations in calcium oxalate nephrolithiasis: two sides of the same coin? Kidney Int 2010, 78:1063-1065

doi:10.1186/1471-2369-13-141

Cite this article as: Albersmeyer et al: Acute kidney injury after ingestion of rhubarb: secondary oxalate nephropathy in a patient with type 1 diabetes. BMC Nephrology 2012 13:141.

\section{Submit your next manuscript to BioMed Central and take full advantage of:}

- Convenient online submission

- Thorough peer review

- No space constraints or color figure charges

- Immediate publication on acceptance

- Inclusion in PubMed, CAS, Scopus and Google Scholar

- Research which is freely available for redistribution 